Article

\title{
Logistics Business Transformation for Sustainability: Assessing the Role of the Lead Sustainability Service Provider (6PL)
}

\author{
Tim Gruchmann ${ }^{1, *(\mathbb{D})}$, Ani Melkonyan ${ }^{2}$ and Klaus Krumme ${ }^{2}$ \\ 1 Faculty of Management, Westcoast University of Applied Sciences, 25746 Heide, Germany \\ 2 Centre for Logistics and Traffic, University of Duisburg-Essen, 47057 Duisburg, Germany; \\ ani.melkonyan@uni-due.de (A.M.); klaus.krumme@uni-due.de (K.K.) \\ * Correspondence: gruchmann@fh-westkueste.de
}

Received: 9 October 2018; Accepted: 26 October 2018; Published: 28 October 2018

\begin{abstract}
Societal, economic and ecological prosperity will be highly affected in the next decades due to socio-demographic developments and climate change. The design of more sustainable logistics business types can address such challenges to build more resilient supply chains. Therefore, the discussion with regard to transformational potentials of logistics businesses provides valuable information to shape business strategies according to future sustainability requirements. Within the framework of this paper, a mixed-methods approach has been applied to explore and analyze drivers and barriers for sustainability transformations of logistics service providers (LSPs) and to evaluate related business strategies with optimization and simulation methods in a concrete regional context. So far, LSPs' main obstacles are competitive pressure, focal firm orientation, and dependence on other supply chain members, while supply chain collaboration and integration, as well as the integration of sharing economy solutions and new digital technologies, have been identified as promising for sustainability transitions. Accordingly, this paper suggests a roadmap for the logistics sector while defining retention strategies such as growth, replication, mimicry, and mergence to meet future societal and environmental requirements. By doing so, this study contributes to theory by constructing the Lead Sustainability Service Provider (6PL) business model (arche)type and its role in societal transitions.
\end{abstract}

Keywords: sustainable logistics; sustainable supply chain management; strategy development; business transformation; business model classification

\section{Introduction}

Several supply chains are likely to drastically change due to regional impacts of climate change, rapid urbanization, demographic developments, and a dynamic shift in demand patterns. Concrete climate protection strategies designed, for example, to prevent $\mathrm{CO}_{2}$ emissions, are therefore being actively pursued by industrial companies [1]. For the logistics industry as such, which is strongly affected by rising fuel prices, more sustainable business activities mean not only a reduction of $\mathrm{CO}_{2}$ emissions and cost savings in economic terms, but also opportunities to highlight the value creation logic of logistics businesses and to allow for new governance forms in the supply chain [2]. In this context, transformational management along the entire supply chain requires integrated solutions considering the main characteristics of business strategies to discuss promising avenues for sustainability transformations [3]. Hence, a better understanding of transformation potentials in the logistics industry will promote the development of innovative, integrative business models based on a strategic roadmap. 
Even though sustainability strategies and business practices in logistics have been intensively discussed in the literature, they have been focused on the economic (optimization of single logistical functions) and environmental dimension (e.g., environmental impacts, such as emissions of transportation activities), underrepresenting the social dimension of sustainability [4]. Also, most research work being done concentrates on the (re-active) adaptation potentials of logistics businesses against the before mentioned challenges rather than discussing pro-active and design-oriented capabilities of logistics to contribute to a sustainability transformation within the frame of alternative sustainable supply chains of a green economy. However, the improvement of social performance within the logistics industry and their societal implications are crucial nowadays since concrete sustainability transformations on the operational levels of economic alternatives are urgently needed as well as scandals and resulting public debates increased the logistical awareness of consumers. Accordingly, the present study intends to contribute by facilitating the understanding of transformation potentials leading to pathways for sustainable logistics business models. Such a perspective of sustainability transformations is essential to understand and overcome existing business model limitations and develop strategies for socio-technical regime changes. Accordingly, the following research questions guided our study:

RQ 1. What are the driving factors and challenges for sustainable logistics business model transformation?

RQ 2. What are transformational pathways for the logistics sector to respond to the requirements of sustainable supply chains?

To answer these questions, the present study combines qualitative methods with optimization and simulation techniques to enhance strategic decision-making. Here, the use of specialized techniques for the sustainable optimization of logistical structures enables decision makers to carry out evaluations of different logistical strategies. As various objectives are explored with qualitative interviews and embedded in an optimization model, the purpose of this study is "exploring" the landscape of plausible outcomes and their relationships with certain decisions. Through applying a representative sample of the search space, the available information for strategic decision-making is evaluated with regard to a concrete regional setting.

The present study is structured as follows. In Section 2, the research is positioned in the existing literature. Section 3 informs about related exploratory modeling and analysis (EMA) approaches. Section 4 describes the research design while the findings are presented in Section 5. Section 6 maps the results with regards to potential pathways for sustainability within the 1PL to 5PL logistics business classification scheme. A discussion of logistics business models in societal transformation processes is provided in Section 7. Concluding remarks and an outlook are presented in Section 8.

\section{Literature Background}

Companies use strategic planning to integrate sustainability within the vision of the company and enhance its innovation potential [5]. In general, sustainability strategies can be linked to environmental marketing management [6], green supply chain management [7], sustainable supply chain management [8], purchasing [9], reverse logistics [10]; and Life Cycle Assessment (LCA) [11]. In addition, all these practices and strategies can be related to socially responsible and green logistics management including the processes of transportation, packaging, and warehousing [12]. For instance, technical innovations and a shift towards transport modes that create the least pollution and strategies promoting multi-modality contribute to more sustainable transport and mobility systems [13]. Here, planning approaches use a variety of static and dynamic models as well as mathematical approximation methods and heuristics to support strategic planning. These approaches focus on different sub-areas such as route planning, location planning, network design, or warehouse planning. With regard to transportation issues, the main goal of most models is to minimize the distance traveled. This can be achieved either directly through intelligent routing (route planning), or indirectly through denser transport capacity utilization (loading space optimization). For this study, routing problems are 
explicitly incorporated into the explorative modelling because of its importance for the sustainability performance in supply chains.

\subsection{Sustainable Logistics Business Models}

Extending conventional business frameworks in accordance with sustainability requirements, Boons and Lüdeke-Freund [14] define the key parameters in sustainable business models as follows: (1) value proposition of products and services focusing on ecological, social, and economic value; (2) overall infrastructure and logistics of the business guided by the principles of sustainable supply chain management; (3) interface with customers enabling close relationships between customers and other stakeholders to improve co-responsibility in production and consumption; and (4) equal distribution of economic costs and benefits among all actors involved. Broadening this systems' scope further, Neumeyer and Santos [15] position business models as part of the whole entrepreneurial ecosystem, particularly dependent on the stakeholder's social network. In addition, Lüdeke-Freund et al. [16] see research in the field of sustainable business models as still limited, particularly with regard to empirical analyses.

In this line, the logistics service providers' (LSPs) potential to facilitate sustainable practices in the supply chains is coming to the fore such that the alignment of logistical actions between actors in the supply chain defines more sustainable and innovative logistics business models [17]. Such industryand branch-specific sustainable businesses can be analyzed to access business model elements and (arche)types that support the management of voluntary social and environmental activities in certain environments [18]. For the logistics industry as such, the business models of shippers and LSPs are categorized by means of their service range and structure. A popular classification scheme is the 1PL to 5PL scheme [19]. Table 1 gives an overview of this classification scheme and related sustainable logistics practices.

Table 1. 1PL to 5PL scheme and related sustainable logistics practices [13].

\begin{tabular}{ll}
\hline \multicolumn{1}{c}{ Classification } & \multicolumn{1}{c}{ Description } \\
\hline $\begin{array}{l}\text { 1PL (Single Service } \\
\text { Provider) }\end{array}$ & $\begin{array}{l}\text { Single service providers execute a single logistics services, such as freight carrier } \\
\text { (transportation) or stock keeper (warehousing). Accordingly, single service } \\
\text { providers should concentrate on methods to decrease the environmental and } \\
\text { social impact of their logistical assets (e.g., using cleaner drive technology). }\end{array}$ \\
\hline $\begin{array}{l}\text { 2PL (2nd Party Logistics } \\
\text { Provider) }\end{array}$ & $\begin{array}{l}\text { The 2nd party logistics provider executes all classical logistics functions of } \\
\text { transportation, handling and warehousing; typical business model for freight } \\
\text { forwarders, ocean carriers and parcel services. As they operate different transport } \\
\text { modes, the selection of the best modal split becomes an important instrument to } \\
\text { increase the environmental performance of their logistical activities. }\end{array}$ \\
\hline $\begin{array}{l}\text { 3PL (3rd Party Logistics } \\
\text { Provider) }\end{array}$ & $\begin{array}{l}\text { The 3rd party logistics provider extends the classical logistics function with } \\
\text { neighboring logistics services such as cross docking, inventory management and } \\
\text { packaging design. In this line, 3rd party logistics providers are often globally } \\
\text { acting companies who contract with their customers "at eye level" [20]. Hence, } \\
\text { they have the opportunity to implement more advanced, sustainable strategies } \\
\text { such as decision support systems to optimize transport mode, route and } \\
\text { capacity usage. }\end{array}$ \\
\hline $\begin{array}{l}\text { 4PL (4th Party Logistics } \\
\text { Provider) and 5PL } \\
\text { (so-called Lead Logistics } \\
\text { Provider) }\end{array}$ & $\begin{array}{l}\text { The 4th party logistics provider provides comprehensive solutions to coordinate } \\
\text { and integrate all supply chain members using information and communication } \\
\text { technologies (ICT). 4th party logistics providers are often specialized consulting } \\
\text { companies not carrying out any operations (so-called non-asset-owning service } \\
\text { providers). In contrast, lead logistics providers carry out certain operations by } \\
\text { owning or buying physical logistics infrastructure. Accordingly, coordination } \\
\text { mechanisms and joint decision-making are relevant to achieve more sustainable } \\
\text { supply chain configurations. }\end{array}$ \\
\hline
\end{tabular}

\subsection{Logistics Business Transformation for Sustainability}

Market innovations that drive sustainable change are often triggered by individuals and companies incorporating sustainability aspects into their core business [21]. Companies can either provide effective solutions to environmental or social problems or sell sustainably produced products 
in the mass market [22]. Taking an evolutionary economics perspective [23], the processes of varying, selecting, and retaining business models induce market transformation [3]. Most of the factors combined into the scenarios lie outside the control of the organization itself, and describe the current trends not only from an economic or technological point of view, but also cover social aspects, e.g., consumer awareness or new sharing models. Taking into account these factors, the present study focuses on potential pathways for the diffusion of sustainable logistics businesses. Here, retention is most important in increasing market share. Retention, in general, describes diffusion processes through innovation promoting growth in the market share of more sustainable businesses. Growth, replication, mimicry, and mergence are seen as retention processes and strategies [3].

Growth: While business growth is often viewed in contrast to sustainable development, the growth of a sustainable business model has to take place at the cost of unsustainable business models. Thus, sustainable growth in consolidated markets acquires a structural market change. To do so, high-growth niche players have to foster radical sustainability innovations in combination with professional management techniques [3]. For the logistics sector, sustainable growth potentials lie within the replacement of conventional transport and warehousing technologies favoring LNG (Liquified Natural Gas), electricity, or hydrogen as energy sources [13]. Here, advanced decision support systems (e.g., for vehicle routing) supported by advanced information technologies, such as big data analytics or artificial intelligence are coming to the fore [1]. Growth potential also lies within the implementation of sustainable reverse logistics practices that guarantee the use and reuse of products. Recently, authors have started to incorporate social aspects in reverse logistics systems, such as equity, diversity, health and safety practices, education, and stakeholder engagement $[10,24]$.

Replication and mimicry: Replication is an alternative form of diffusion. Here, niche pioneers set up a sustainability-oriented business model solely applying sustainable ways of production and were followed by other niche players. Mimicry describes the strategy of copying business model elements of niche businesses and incorporating them in a modified way into a mass market player's business models. For the logistics industry, start-up businesses with a city logistics focus provide the potential for replication and mimicry as they allow for alternative transportation modes such as cargo bikes, private or public transportation. In crowd logistics businesses, for instance, the offered services are mostly fulfilled by consumers and not by the staff of a company [25]. Accordingly, these allow for an inclusion of private persons to conduct logistics activities. Here, replication and mimicry strategies are promising the field of sharing economy businesses as shared consumption has the potential to raise the awareness for ecological and social aspects related to distribution channels [26]. In addition, circular economy business models provide the potential to leverage LSP's sustainability potential [27].

Mergence: Mergence has been studied mainly from the perspective of mass market players through the acquisition of promising niche players. If companies do not compete directly, they can also build strategic alliances such as strategic partnerships. Thus, a balance between a customer orientation and operating cost-effectively can be also achieved through supply chain coordination. In this context, supply chain coordination is defined as coordinating cross-company activities on a vertical and horizontal supply chain level to share risks and rewards in a fair manner [28]. Accordingly, logistical infrastructure has to be shared and combined effectively to achieve better sustainability.

\section{Exploratory Modeling and Analysis (EMA)}

EMA aims to utilize the advantages of computer-aided simulations and experiments when it comes to decision-making where a significant amount of uncertainty is present [29]. Within EMA, exploration procedures are conducted via computer-aided experiments. One single run of the computer aided experiment (calculation run) is performed with a model that has a given structure and a given parameterization. Here, a calculation run based on the input of fixed data represents a single estimate of the future. Conducting a large number of calculation runs (performed with one or several models), a structure for likely actions and sequences of events can be derived. These possible outcomes arise by making alternative decisions assuming different, unknown future events. Accordingly, 
different possible scenarios can be explored. Therefore, EMA is not about optimizing the outcome of possible solution through the evaluation. Rather, the possible "what-if" questions are supposed to be clarified [30,31]. Hence, the most important goal of EMA is to find the most robust decision paths to cover a variety of future scenarios [31,32]. Accordingly, strategic pathways are robust in the face of uncertainty when its actions perform satisfactorily over a wide range of future situations.

So far, there have been few studies that use exploratory modeling for supply chain or logistics issues. For instance, Kwakkel et al. [33] developed an Adaptive Airport Strategic Planning (AASP) approach based on the more common Airport Master Planning (AMP) for the development and expansion of airports. They used exploratory modeling to test the efficacy of their AASP for a variety of future scenarios concerning Amsterdam Airport Schiphol. Moreover, Halim et al. [34] dealt with EMA and scenario discovery regarding the impact of deep uncertainty on global container transport in European ports. These authors combined the concept of scenario discovery with an additional worst-case discovery technique. In addition, Corvers [35] conducted a scenario discovery in the context of Supply Chain Risk Management. Factors that were tested are warehousing decisions and various common risks coming from business and customer demand. Just recently, Mollaemi et al. [36] used a scenario discovery approach based on a hypothetical air fleet. It deals with the trade-off between maintenance services and aircraft investments with the aim of maximizing flight hours and keeping investment and service costs to a minimum. In contrast to the previous studies, the present study focuses on the application of EMA-based techniques (optimization and simulation) for analyzing potential pathways for LSPs in a specific regional setting based on a more general, qualitative exploration. To the best of our knowledge, none of the previous studies tackled the proposed research questions so far.

\section{Research Design}

In general, a mixed-methods approach was applied to explore relevant driving factors and barriers for sustainability transitions of LSPs (see Section 4.1), as well as to analyze and evaluate related transformational strategies within a concrete region, in particular the Linz region in Upper Austria (Section 4.2).

\subsection{Qualitative Exploration}

In order to study transformational potentials of logistics business models, drivers and barriers influencing the sustainability performance of the supply chain were identified through qualitative expert interviews and discussed within a participatory workshop. Since the research interest particularly addresses logistics services, the qualitative interviews were held with experts in the field of supply chain and logistics services, as well as in consumer lifestyle. All the specialists had at least five years of experience in their field. Regarding the expert interviewee selection, six interviewees were chosen from a group of scientists (professors) holding a chair in logistics and SC management at European universities, while the other six interviews were conducted with scientists whose research is focused on sustainable consumption and production. From the practitioners' side, three interviewees were selected from sustainability managers who work with Western European LSPs, while three interviewees worked with Western European non-governmental consumer organizations (see Table 2). In sum, 18 qualitative expert interviews were conducted based on an interview topic guide (see Appendix A). The interviews lasted up to $60 \mathrm{~min}$ and were tape-recorded or transcribed with important quotes summarized. The transcripts, summaries and important quotes were analyzed with the qualitative content analysis approach in a structured, inductive manner [37] and linked to the literature, whenever possible. 
Table 2. Interviewee settings and expertise.

\begin{tabular}{ll}
\hline Index & \multicolumn{1}{c}{ Setting and Expertise } \\
\hline Practitioners \\
\hline P1 & German third-party food logistics provider \\
P2 & German third-party fashion logistics provider \\
P3 & Austrian third-party food and FMCG logistics provider \\
P4 & German consumer advice agency \\
P5 & Irish consumer engagement and information center \\
P6 & Finnish sharing economy expert \\
\hline Scientists in the field of (sustainable) logistics and SC management \\
\hline S1 & Professor in transport and logistics management \\
S2 & Professor in retail logistics \\
S3 & Professor in SC management \\
S4 & Professor in logistics and service management \\
S5 & Professor in SC management \\
S6 & Scientist working in a research institute concerned with mobility research \\
\hline Scientists in the field of (sustainable) consumption \\
\hline S7 & Professor of consumer and household economics \\
S8 & Scientist in research group concerned with sustainable consumption and production \\
S9 & Scientist in research institute concerned with responsibility research \\
S10 & Scientist in research institute concerned with social innovation \\
S11 & Scientist in research center concerned with environmental economics \\
S12 & Scientist in research concerned with environmental economics \\
\hline
\end{tabular}

Due to the complexity of qualitative interviews, careful interpretations of the interview results are necessary to analyze the extent to which the findings serve the research purpose [38]. According to Yin [39], quality procedures with regards to internal validity, external validity, construct validity, and inter-rater reliability need to be in place when analyzing qualitative data and documents to ensure methodological rigor. Regarding internal validity, the transcript coding was performed by two researchers, also ensuring inter-rater reliability. To further strengthen internal validity, the insights from the expert interviews were triangulated with the data from the consumer interviews. In terms of external validity, comparisons with literature were conducted, as suggested by Riege [40]. To further strengthen external validity, an expert workshop was performed with scientific participants from various German universities (none of whom was an interviewee) discussing the approach to evaluate the inductive coding scheme as well as the strategic categories derived from the qualitative content analysis approach. Construct validity was built by collecting data from multiple sources, while reliability was achieved by exposing relevant parallels across multiple sources.

\subsection{Strategy Evaluation}

To evaluate the observed business strategies in a concrete setting, synthetic data were generated to simulate the peri-urban and socioeconomic characteristics of the Linz region in Upper Austria. Generally, generating a synthetic population is useful when real data are not (yet) available, in particular when testing future strategic scenarios [41]. In this line, agent-based models such as traffic models require explicit assumptions about individuals or households. Therefore, synthetic data about households require datasets that preserve the statistical characteristics of the entire population. To generate the synthetic data, in a first step, all buildings in the concrete region of Linz were retrieved from OpenStreetMap (OSM). These buildings were filtered to include only private housing. Each house was randomly given socioeconomic parameters such as income, number of adults and children in the household as well as car ownership. The probability of owning a car is based on the income in the household. In a second step, the logistics network is constructed to apply for certain sustainable logistics strategies. Such a logistics network consists of specific facilities, in particular plants, warehouses, distribution centers (DCs), and customers. Assuming that plants and consumers are fixed locations, strategic decision-making on certain retention strategies is concentrated on DCs in 
terms of the optimal number and location [42]. Accordingly, the locations of DCs were calculated using $\mathrm{k}$-means clustering algorithm [43]. The k-means clustering algorithm produces different results, with each calculation run given a fixed input. Therefore, the calculation with k-means was run 100 times and the results were averaged. An example of 10 DCs is illustrated in Figure 1.

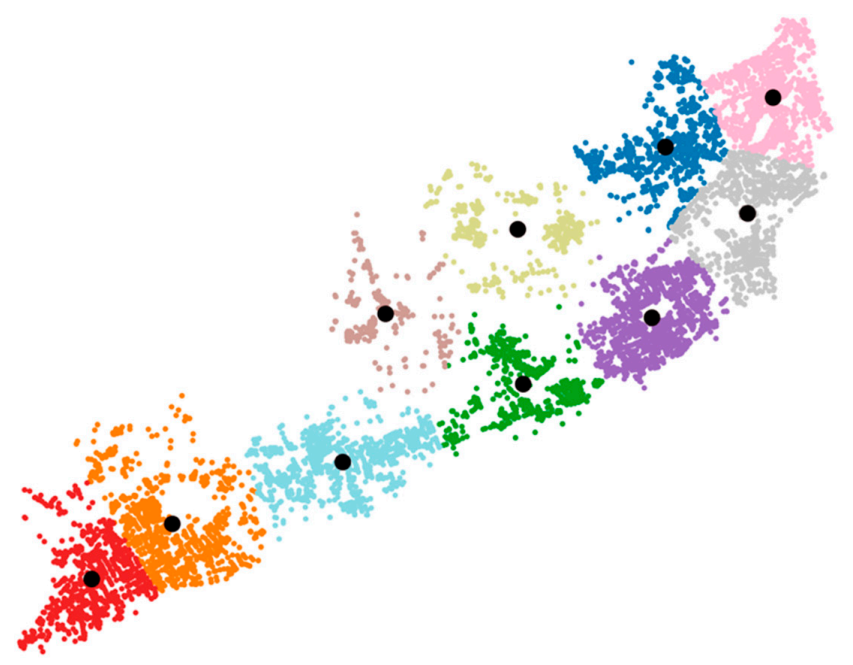

Figure 1. Facility location.

Once DCs were defined by k-means, route optimization and the underlying Traveling Salesman Problem (TSP) with starting point and end point being the same DC was carried out [44]. Figure 2 illustrates an example of the shortest route visiting eight DCs. The TSP was solved by using closest neighbor heuristics and by applying a two-opt algorithm to improve the initial solution.

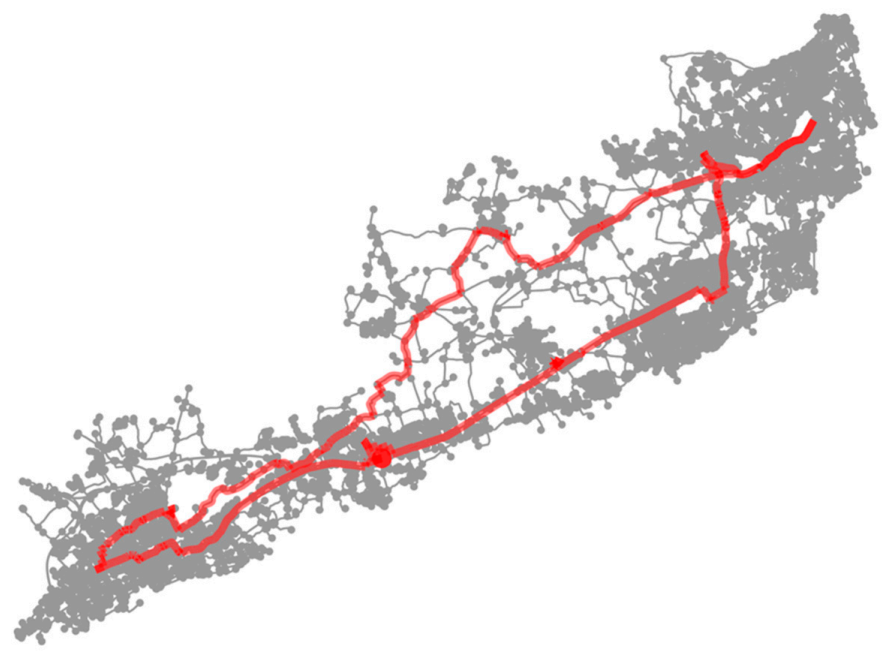

Figure 2. Route optimization.

To model individual agents (households) with numerous decision possibilities, parameters were included that control the behavior of households. Each of these parameters represent a conditional, discrete probability distribution, which defines, for instance, the degree of contributing to an action of interest based on belonging to a socioeconomic class. These probability distributions were subject to Monte Carlo simulation experiments in a third step. These result of the Monte Carlo simulation were further coupled with certain transformational pathways to derive insights for business decision-making [36]. 


\section{Findings}

By analyzing the interview data, structural dimensions describing current challenges (Section 5.1), driving factors and emerging trends (Section 5.2) were derived. These findings were linked to the literature in order to refine business transformation strategies for sustainability (Section 5.3). In a last step, related last-mile strategies were evaluated for the Linz region in Upper Austria (Section 5.4).

\subsection{Transformation Challenges}

"If a logistics service provider, for instance, would run an online supermarket and, at the same time, offering transportation services to retailers, this would cause a clear conflict of interest. The logistics service provider would be a competitor to its own customer. This is not our self-comprehension." (P1)

In the experts' opinion, the focal company in the supply chain is still the main trigger for adopting technologies and practices that result in labor practices considered to be fair, and that result in a lower impact on the environment (P1; P2; S1). Despite external pressures on focal companies to act sustainably, a strong focal firm orientation might also prevent LSPs from implementing further sustainable practices considering the empirical results. With regard to communication of sustainable aspects, for instance, retailers need to strengthen the value of their brand to differentiate themselves from competitors as cross-company retailing slackens the consumers' brand loyalty to a single trading firm (P1; P3). Although LSPs and retailers need to cooperate to achieve a clear and consistent communication about sustainable logistics aspects, retailers have little interest in doing so, fearing the dilution of their own brand identity (P1; P3).

Moreover, there is a need for LSPs to guarantee minimum social standards due to the increasing internationalization of the logistics industry (in line with the engagement of foreign employees, often employed through sub-contractors) (S1; S5). Therefore, the experts highlighted the importance for compliance with social and legal standards when operating logistics across borders (P1; P2; P3; S2). In contrast, the retailers' high price sensitivity concerning logistics services (e.g., as a consequence of not charging shipping costs to the consumer) supports a low consumer willingness to pay for logistics services (P2; P3; S1; S2; S4). However, some of the interviewees did not exclude consumers who are willing to pay more for better sustainability performance, particularly those target groups that are open-minded toward social and ecological issues (P1; P2; P3; S2; S4). To meet this goal, it would be mandatory to coordinate pricing activities across the whole supply chain to assure social logistics standards (S2). Currently, the experts see rather small chances to realize such a transformation due to the high competition within the logistics industry (P1; P2; P3; S2; S4; S5). Nonetheless, logistics-oriented retailers, such as Amazon, are already changing consumers' attitudes toward new business practices, creating new competitive pressures for "traditional" business practices that may lead to structural changes within supply chains.

\subsection{Transformation Drivers}

"I think, the problem is, the industry is changing, the social structure is changing, and the technology is changing. Logistic service providers have to either follow or lead these changes. Certainly, one logistic service provider, one company does not have enough room, [ ... ] skills and the resources to make this change happen. So, in that case, collaboration, establishing joint trading programs, defining what will be required in the next five to ten years, being proactive is the key in my opinion." (S4)

The interviewees stressed the importance of coordinating activities among the supply chain actors (S1; S2; S3; S4; S5). During the interviews, the question of how to configure supply chains under such conditions was discussed. With regard to trends like leasing or renting vehicles and warehouses, the interviewees focused on the shared use of resources and infrastructure among LSPs (P1; P6; S3; S4; S6; S10; S11). Here, several 3PLs providers no longer operate their own truck fleet in favor of coordinating material and information flows (P1; P2; P3). On the one hand, this was seen as a chance 
for sustainable logistics services since, for instance, the cross-company use of vehicles might also support conversion to alternative technologies (like e-mobility), which are currently too expensive for one single company to operate (P1; P6; S6). On the other hand, these practices were controversial when discussed by the interviewees. They argued that a paradigm shift is required to achieve stronger horizontal collaboration (P1; P2; P3; S3; S4). For instance, truck drivers would have to share their vehicles and retailers would need to lower their competitive foreclosure thinking in consolidating commodity flows (P1). Currently, the experts see better chances to gain efficiency potentials for the supply chain by the joint development of advanced technologies (S2; S3; S4; S6).

In addition, possibilities to expand logistics service offerings on a vertical supply chain level in regard to manufacturing (e.g., by using 3D printing) and to online retailing were discussed in the interviews (P1; S2; S4; S8). With 3D printing, a more sustainable supply chain configuration is achievable in terms of decentralized production (S2; S4). 3D prints can be produced in LSPs' warehouses, or the printing raw material can be supplied for production directly at the consumers' site (S4). This change would simplify the supply chain configuration and reduce efforts (e.g., less traffic). Although technological innovations, such as 3D printing on a vertical level or e-mobility on a horizontal level, would provide the opportunity to strengthen the position of LSPs and, at the same time, enforce a more sustainable supply chain configuration, many interviewees recognized that such an implementation might be difficult (P1; S2; S4; S8). Due to the role of LSPs as a link between manufacturer, retailer, and consumers, a strategic reorientation that extends the LSPs' portfolio might conflict with the interests of other supply chain actors (P1). In the opinion of the interviewees, the highest potential for sustainability currently lies in professionalizing online retailing in terms of last-mile logistics: for example, by bundling cross-company commodity flows (P2; S2).

From the interviewees' point of view, the trend of the sharing and circular economy businesses has the potential for more sustainable configurations of business-to-customer relationships in general, and last-mile logistics in particular (P2; S2; S4; S8; S10; S11). In this line, shared consumption considerably affects last-mile logistics since products must be transported by consumers to consumers (S11). During the interviews, the question of how to configure last-mile logistics was discussed, with a focus on crowd logistics business models (S2; S4). The interviewees mentioned storage services, freight shipping, local delivery services and freight forwarding as the most promising trends in the sharing economy with regard to logistics professionalism and sustainability impact (P2; W2; S4; S8; S10; S11). However, in the opinion of the interviewees, the sharing economy business practices still require further logistical professionalism to cope with system and technological complexity (S8; S10; S11). Moreover, the interviewees considered logistics practices carried out by private parties to be controversial, also to close cycles. The current social performance of sharing services is the main argument against this form of last-mile configuration, since an official registration, compulsory insurances, and load protection are missing (P2; S2; S4). Accordingly, logistical sharing and circular economy practices should assure at least the social minimum standards including fair wages, compulsory insurances, and accident prevention regulations.

"New logistic service providers are coming, trying to develop peer-to-peer services in order to facilitate the exchange of logistics services on a platform. [ ... ] In the sharing economy, you need some logistics that can be done by the consumers themselves." (W11)

\subsection{Synthesized Empirical Results}

During the interviews, LSPs' main obstacles and drivers in enhancing their sustainability activities were investigated. These obstacles are competitive pressure, focal firm orientation, and dependence on other supply chain members. Secondly, the expert's implications are presented regarding the factors and trends that drive the application of sustainable logistics practices beyond current activities. In particular, supply chain collaboration and integration, as well as the integration of sharing economy solutions and new digital technologies, have been identified through the qualitative content analysis approach. Mapping logistics businesses in a wider entrepreneurial ecosystem, classical and future 
sustainable logistics business models can be derived and clustered in accordance to retention processes and strategies. In this line, the empirical results suggest at least three transformation pathways for sustainability with regard to the single retention strategies of growth, replication/mimicry and mergence, which are evaluated and discussed in the next sections. So far, the empirical data indicate that growth and in particular mergence strategies are most promising for the logistics industry while replication/mimicry rather have the potential to complement the other pathways. Table 3 synthesizes the empirical results with regard to the 1PL to 5PL logistics businesses classification scheme and related retention strategies.

Table 3. Observed sustainable logistical strategies from the expert interviews.

\begin{tabular}{|c|c|c|c|c|}
\hline Classification & Growth & Replication & Mimicry & Mergence \\
\hline 1PL (Single Service Provider) & $\begin{array}{l}\text { Increasing use of cleaner } \\
\text { technologies }\end{array}$ & New (digital & echnologies & $\begin{array}{l}\text { Shared use of } \\
\text { infrastructure }\end{array}$ \\
\hline $\begin{array}{l}\text { 2PL (2nd Party Logistics } \\
\text { Provider) }\end{array}$ & \multirow{2}{*}{$\begin{array}{l}\text { Advanced decision } \\
\text { support systems }\end{array}$} & \multirow{2}{*}{\multicolumn{2}{|c|}{ Crowd logistics solutions }} & \multirow{2}{*}{$\begin{array}{l}\text { Multi-modal } \\
\text { transportation }\end{array}$} \\
\hline $\begin{array}{l}\text { 3PL (3rd Party Logistics } \\
\text { Provider) }\end{array}$ & & & & \\
\hline $\begin{array}{l}\text { 4PL (4th Party Logistics } \\
\text { Provider) and 5PL (so-called } \\
\text { Lead Logistics Provider) }\end{array}$ & $\begin{array}{l}\text { Last-mile and reverse } \\
\text { logistics integration }\end{array}$ & $\begin{array}{l}\text { Sharing and } \\
\text { economy bus }\end{array}$ & $\begin{array}{l}\text { cular } \\
\text { esses }\end{array}$ & $\begin{array}{l}\text { Supply chain } \\
\text { coordination }\end{array}$ \\
\hline
\end{tabular}

\subsection{Strategy Evaluation}

To evaluate the derived transformation pathways, the required logistics infrastructure is a most crucial. Therefore, an important decision variable in the modeling is the number of DCs determining the realization of last-mile and reverse logistics integrated supply chains as well as logistically coordinated sharing and circular economy businesses. In this line, the number and density of DCs defines strategic potential, such as potential growth through additionally generated demand and mergence potentials to increase efficiency. While a solely economic perspective primarily fosters the expansion of market shares and the reduction of operation costs, a holistic perspective fosters also alternative transportation modes, such as cargo bikes, private car use, or even walking distance as well as logistically enabled sharing and circular economy businesses. The evaluation of the required infrastructure in the concrete setting fostered the analysis of how different numbers of DCs affect the average distances to enable alternative transportation modes and consumer-centered logistics services such as delivery services (see Figure 3).

Such an analysis gives insights where thresholds exist that allow certain business practices in a peri-urban area such as the Linz region. For instance, if $3 \mathrm{~km}$ is a threshold for using a cargo bike, then there is little motivation to establish more than $10 \mathrm{DCs}$. The total length of transporting goods (milk-run based on TSP) and consumer trips (from private households to the closest DC) is shown in Figure 4. Here, an increasing number of DCs decreases the total travel length. While this analysis can be useful for deciding on the number of DCs, however, it does not take into consideration the consumers' mobility behavior. Therefore, the analysis was extended by a simulation approach to construct certain scenarios. Figure 5 illustrates the customers' distance to the nearest DC while Figures 6-8 illustrates a single run of a Monte Carlo simulation for a given parameterization and five DCs. These results are based on individual purchasing choices that are determined by income, number of people living in a household, and whether a consumer owns a car or not. Accordingly, the mode of transportation (bike, car or walk) is also determined by these factors.

Evaluation of growth strategies: Generally, the use of decision support systems for location planning and vehicle routing allows for a more efficient and sustainable growth to achieve last-mile and reverse logistics integration. In particular, Figure 5 illustrates that the median distance to the closest DC can be reduced far below $2000 \mathrm{~m}$ if a sufficient infrastructure is in place. Nonetheless, the related investments in additional DCs need to be economically justified when it comes to balancing the single 
sustainability dimensions. So far, the existing barriers such as the high competition in a specific region rather frustrate sustainable growth strategies lead by LSPs. However, logistics-oriented retailing companies such as Amazon are currently favoring power shifts in the supply chain. In addition, white-label logistics solutions fostered by municipalities might also have a positive influence in achieving the required infrastructure density.

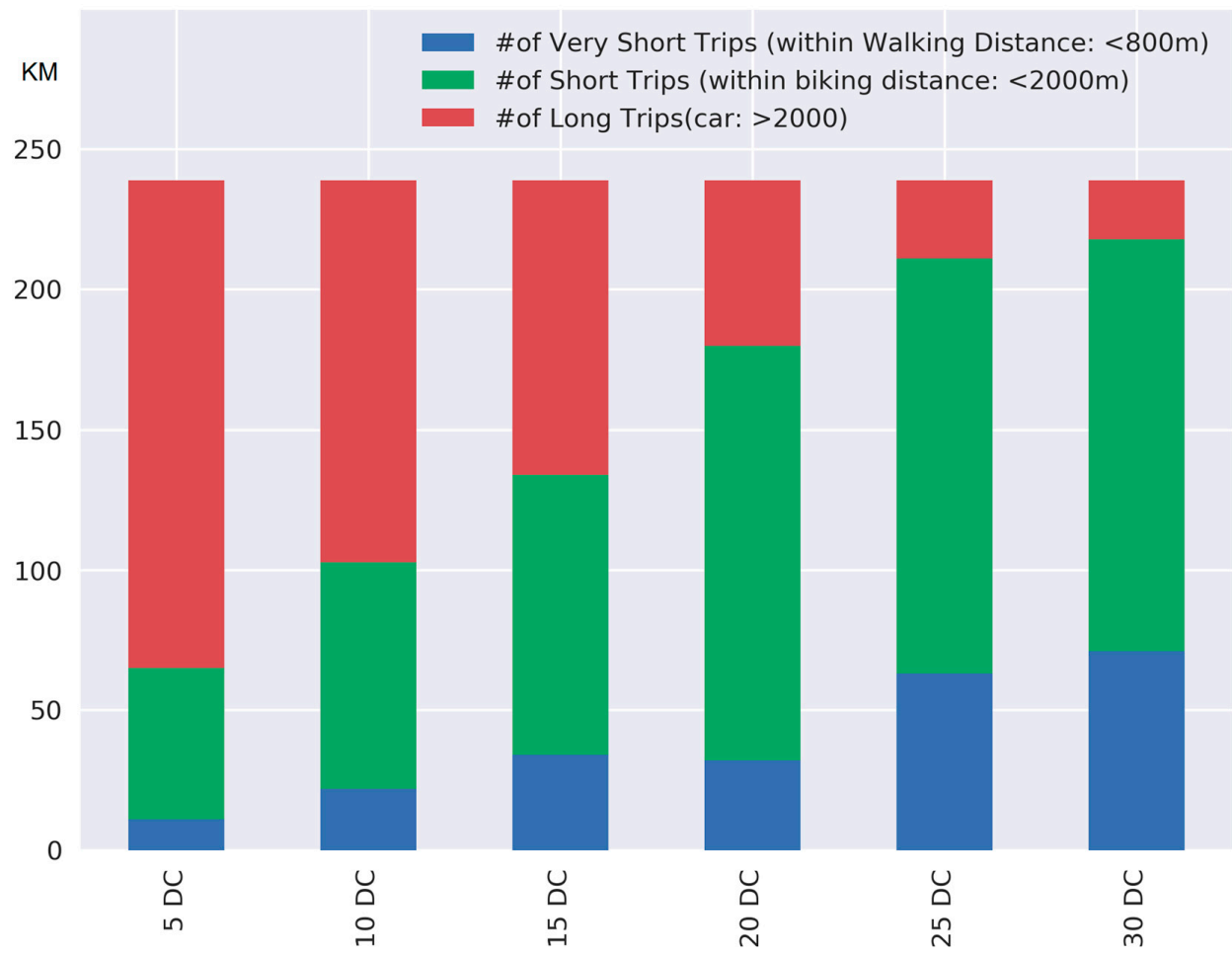

Figure 3. Analysis on an aggregate level.

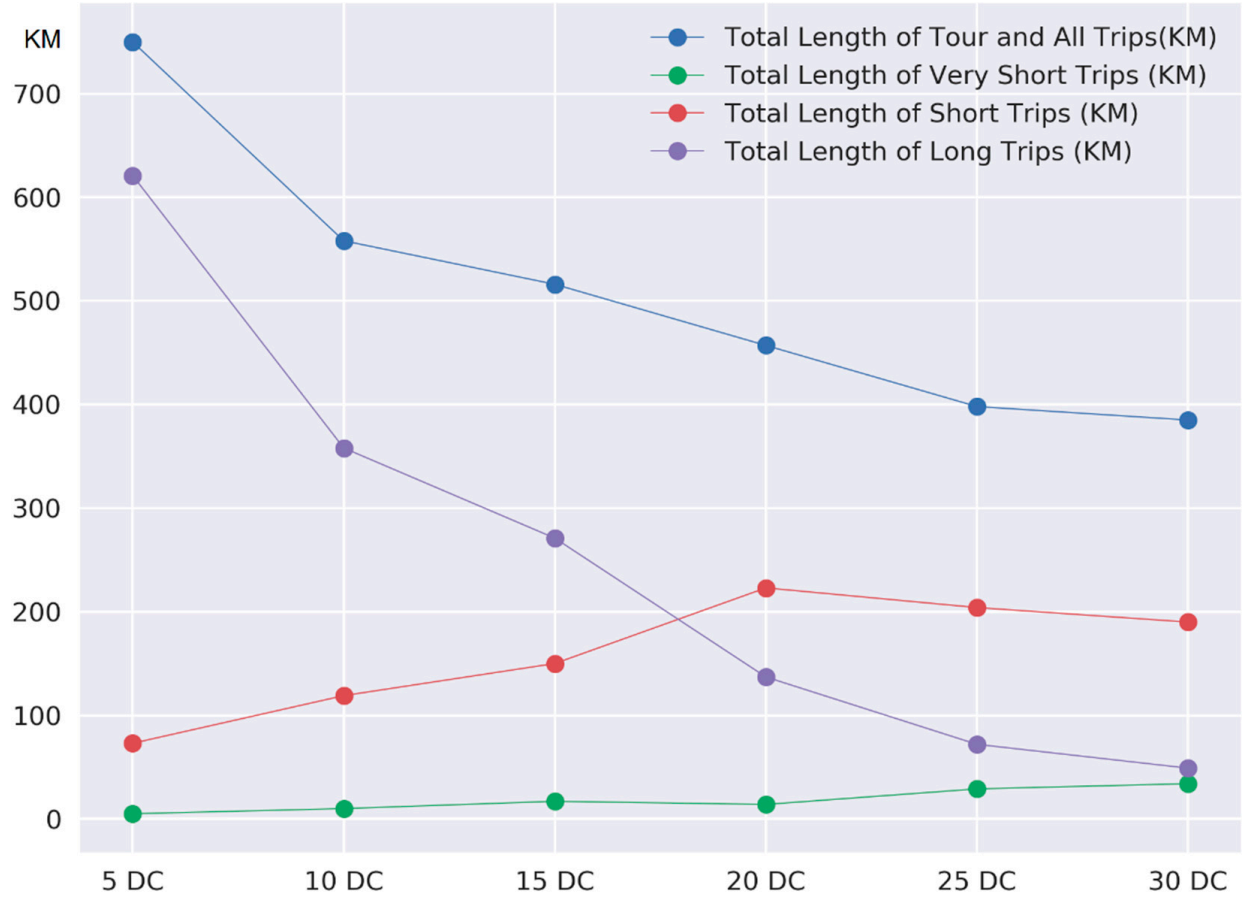

Figure 4. Total length of trips. 

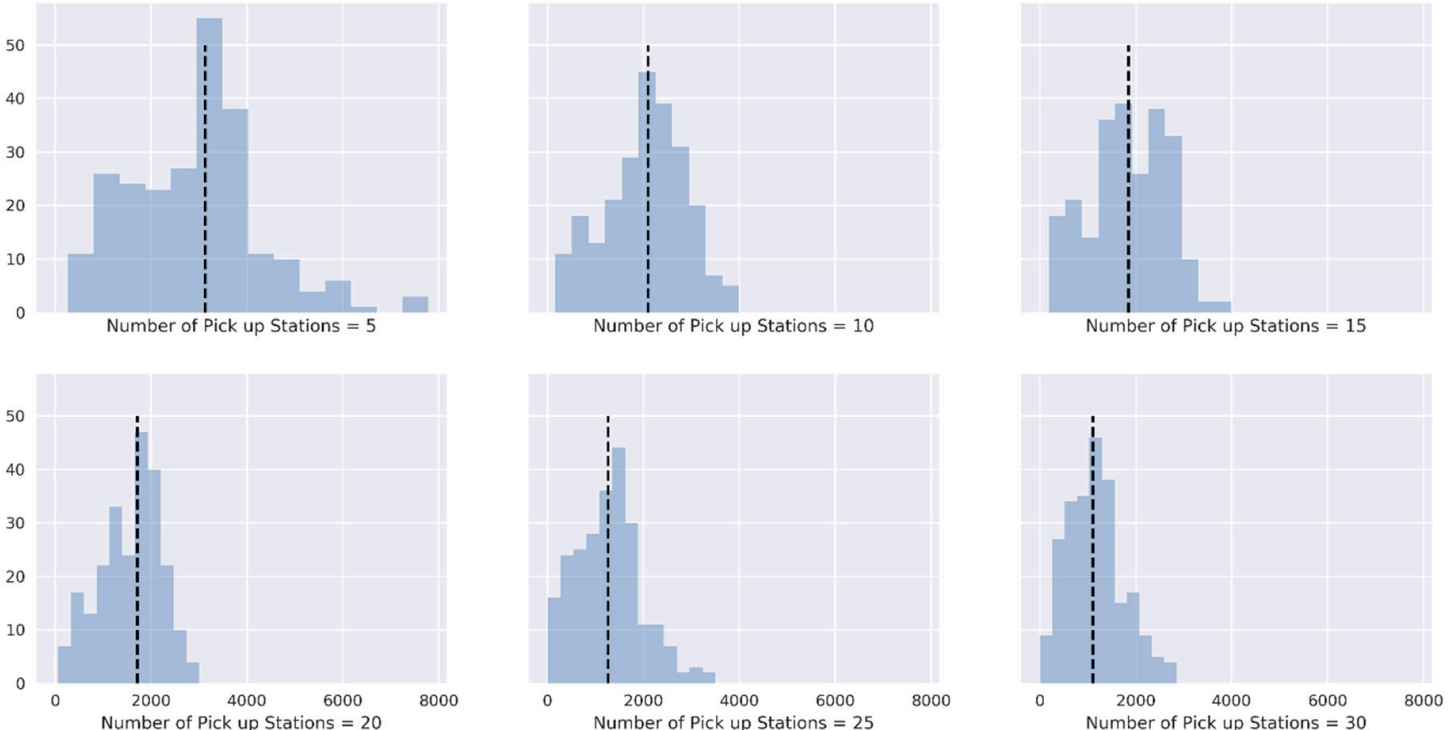

Figure 5. Customer distance to the nearest DC in meters (dashed line represents median value).

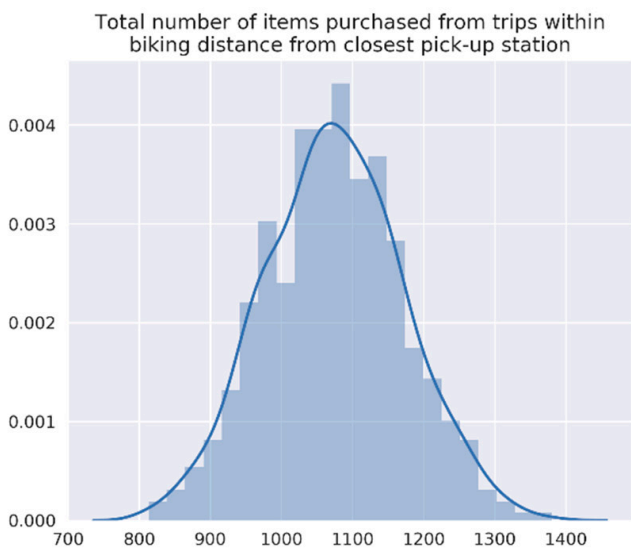

Total length of trips within biking distance from closest pick-up station (meters)

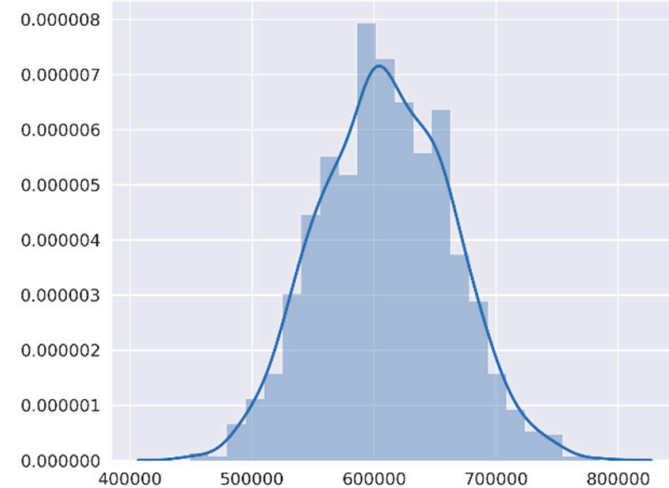

Figure 6. Total number of purchases from trips within biking distance.

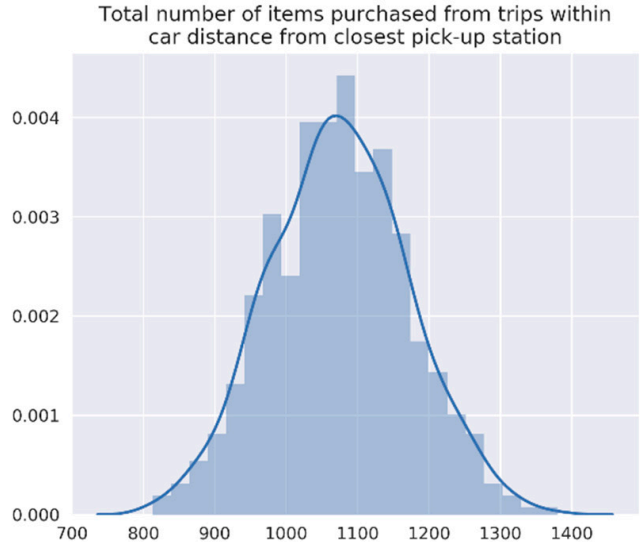

Total length of trips within car distance from closest pick-up station (meters) 0.000006

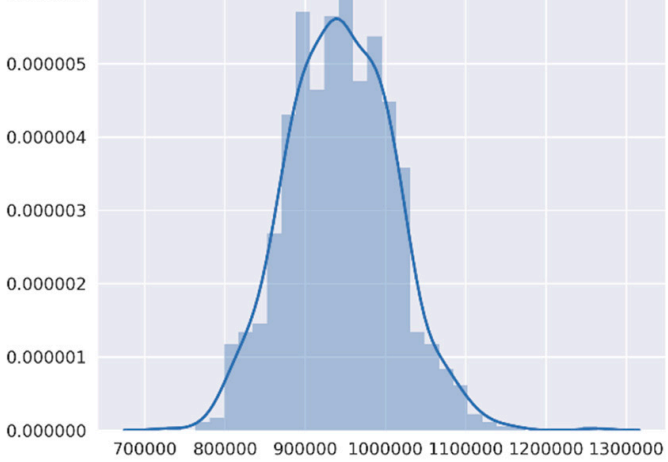

Figure 7. Total number of purchases from trips within car distance. 

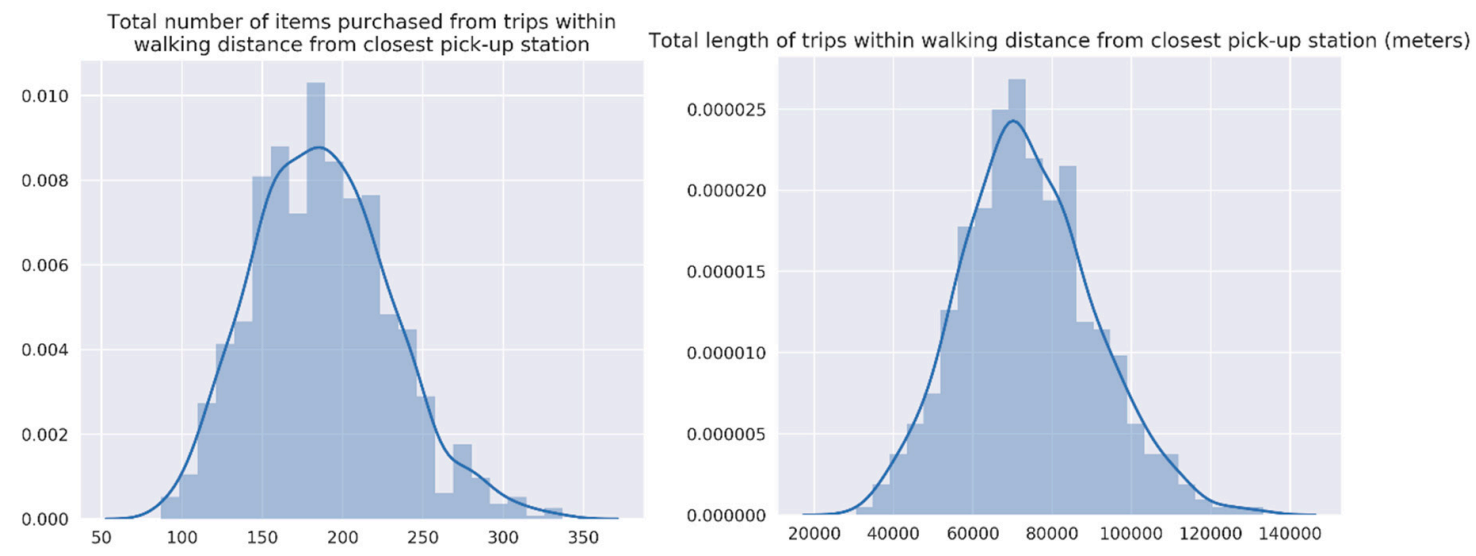

Figure 8. Total number of purchases from trips within walking distance.

Evaluation of replication and mimicry strategies: While the emphasis was put on the essential network elements of facilities and transportation modes to evaluate more green and sustainable network designs, relevant insights with regard to promoting alternative transportation modes in walking or biking distance could be derived. Assuming a threshold of $2000 \mathrm{~m}$ as biking distance, for instance, 20 DCs guarantee the maximum total length of short trips in the region of Linz (see Figure 4). Accordingly, the inclusion of private persons to conduct logistics activities is possible and promising for a future sharing economy and circular economy businesses to further leverage LSP's sustainability potentials. However, the required logistical infrastructure is a necessary prerequisite for replication and mimicry strategies and, therefore, their realization continues growth and mergence strategies.

Evaluation of mergence strategies: To achieve a high coverage also in peri-urban areas, such as the Linz region, existing opportunities should be activated through a shared use of infrastructure, e.g., through collaborating with other retail stores or restaurants. In order to realize a higher sustainability performance, warehousing infrastructure can be shared and combined more effectively constructing a network of micro hubs and depots to also allow for alternative transport modes. Accordingly, the evaluation of the derived transformation pathways confirms the qualitative, empirical results and points to the growth and mergence strategies as the most promising in the near future.

\section{Road Mapping to Include LSP Pathways for Sustainability}

To allow for a structured discussion of potential transformation pathways for sustainability, the existing 1PL to 5PL business model (arche-)types are incorporated into a transformation roadmap (see Figure 9). In the following, the 1PL to 5PL classification scheme is discussed taking into account current business developments and challenges, in particular the observed challenges coming from e-commerce and multi-/omni-channel retailing. These business challenges have been changing in the past from subcontracting (1PL) and globalization (2PL) towards e-commerce and omni-channel growth (3PL to 5PL). Solutions for these challenges have also been strongly driven by transformations in the past, starting from the planning of locations and vehicle routing (1PL) towards advanced ICT (2PL), cross-docking (3PL), and advanced pooling (4PL to 5PL). Combining these challenges with possible solutions allows for the inclusion of a new business model (arche)type to the 1PL to 5PL scheme, the so-called Lead Sustainability Service Provider (6PL). The 6PL not only extends the existing 1PL to 5PL scheme, but also represents the target course of the transformation roadmap. As a developmental option, 6PL was part of the ILoNa research designs that led to this paper's underlying research activities (see Acknowledgments).

Single Service Provider: With regard to multi-channel grocery retailing, 1PLs either run distribution centers to store products or carry out transports between suppliers, distribution centers and retail stores [45]. In addition, picking processes can be carried out as contract logistics services by 1PLs. Within those conventional business models, transformation potentials lie not just in the application of cleaner technologies but also in the inclusion of new (digital) technologies. However, subcontracting 
as practice to achieve a high regional coverage will remain such that 1PLs are an important part of growth and mergence strategies of 4PL-5PL companies. Therefore, 4PL-5PL companies have to assure social standards when outsourcing single logistics activities.

2nd Party Logistics Provider: With regard to online retailing, last-mile delivery services of groceries are becoming more relevant for 2PLs in the near future, in particular for parcel service providers. Due to nature of food products, requirements considering hygiene, perishability as well as packaging and labeling [46] are also tackling service providers in the last mile. Hence, specific packaging (isolated boxes) or transport processes (in different temperature zones) might have negative impacts on the sustainability performance [47]. As 2PLs already coordinate limited parts of the supply chain such as the last mile, advanced decision support systems are coming to the fore to decrease the travel distance and increase the drop-off rate. In addition, 2PLs have the replication and mimicry opportunities to include consumer in crowd logistics businesses. However, such business need, once again, assure social standards as well as the necessary procedures to assure quality procedures.

3rd Party Logistics Provider: 3PLs are generally capable to run omni-channel distribution channels and, therefore, can include mergence strategies such as multi-modal transportation. However, decentralized organizations like cooperatives have more and higher hurdles when implementing centralized online solutions and distrust logistics service providers when it comes to a safe handling of food products [47]. This is why omni-channel retailers often deliver their products by themselves rather than using a 3PL. Accordingly, 3PLs might have to include retailing activities in their business portfolio in line with a sustainability growth strategy. Although new players in the market, such as Amazon, are following such a strategy, established LSPs might fear to lose retail customers by pursuing such a way.

4th Party Logistics Provider and Lead Logistics Provider: 4PLs and 5PLs have the opportunity to realize more alternative business models through the concrete integration of consumer-centered businesses such as circular and sharing economy solutions in their service portfolio to achieve further positive sustainability effects. A prerequisite for such alterative businesses is that coordinated, and logistically integrated supply chains are in place. Accordingly, growth and mergence strategies lie the basis for a strategy development towards the development into a 6PL. Such a development allows for new solutions that include advanced sustainability performance goals into conventional logistics businesses as well as empower consumers for logistics prosumption activities [48].

Lead Sustainability Service Provider (6PL): Constructing a 6PL business (arche)type, a consumer-choice-centered perspective is important to resolve existing barriers such as the willingness to pay for logistics services or the realization of a higher social and societal performance. Hence, LSPs need to include consumers directly into their business strategies and communicate related activities. In this line, a closing of business cycles has to bridge the last mile as a crucial point to achieve supply chain and reverse logistics integration. Possible practices in this direction are the sharing of existing infrastructure and the building of alternative (transportation) systems such as the use of cargo bikes. However, dependence on other supply chain members as well as fierce competition is still seen as a major challenge for LSPs to implement such sustainable practices. Accordingly, LSPs would gain from potential pathways that stress anti-competitive and performance enhancement purposes. In this line, new (digital) technologies as well as consumer empowerment play an important role to also pursue replication and mimicry strategies. 


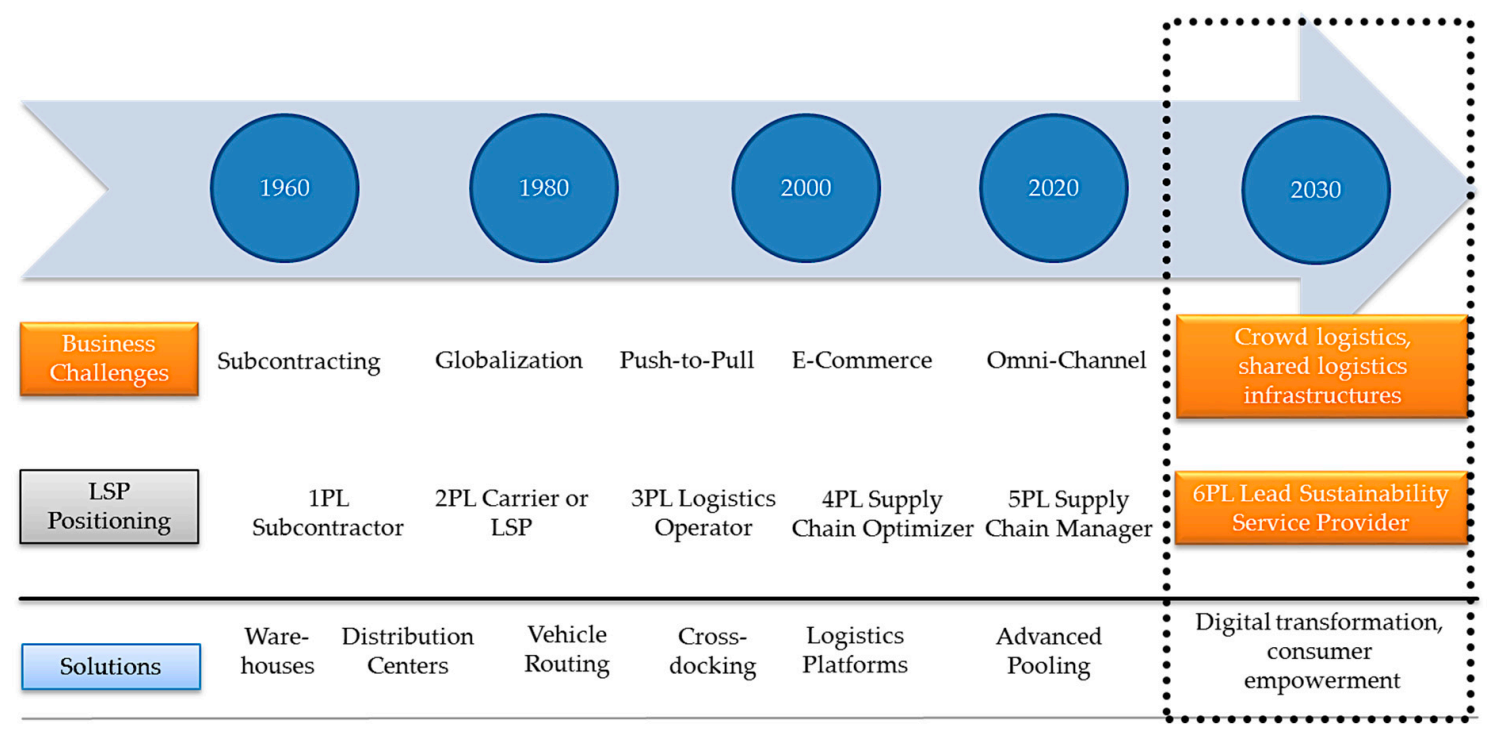

Figure 9. LSP's sustainability roadmap.

\section{Discussion of Societal Transitions and Related Logistics Strategies from a Business Model Perspective}

So far, competition within the logistics industry is preventing a transformation in direction to a more sustainable supply chain configuration. Therefore, the existing logistics business model (1PL to 3PL) hampers transitions by reinforcing the current system's stability [49]. As these business models are part of the current socio-technical regime and apply the dominant regime logic [49], LSPs mainly adapt to environmental "stand-alone" practices in transportation and packaging and assure the minimum social standards required by external stakeholders so far [50]. Accordingly, many interviewees recognized that due to the role of LSPs as link between manufacturing, retailing, and consumer, a strategic extension of the LSPs' portfolio might conflict with the interests of other supply chain members. However, the findings provide evidence that growth and mergence strategies allow further sustainability improvements of the existing system, at least to a certain extend. Here, also 4PL and 5PL companies have the opportunity to increase the sustainability performance by governing fast parts of the supply. Nonetheless, there are currently just a limited number of 4PL and 5PL companies in the market able to pursue such strategies. However, technological innovations provide the opportunity to strengthen the position of 3PLs in the supply chain and, at the same time, grow in the direction of a 5PL with the required logistical infrastructure.

A second option for a transition of the existing system lies in the potential of LSP's business models to act as an intermediary between technological niche players and the socio-technical regime [49]. Here, replication and mimicry strategies allow LSPs to implement sustainability-oriented business practices from niche pioneers in their own business portfolio such as crowd logistics, sharing or circular economy business practices. Currently, these business practices might not be profitable but allow for achieving consumer-choice-centered logistical services. In particular, those businesses that incorporate the last mile have the opportunity to implement a 6PL business model. In this line, alternative transportation modes could weaken the pricing pressure on logistics services. However, the current findings indicate that such a pathway is unlikely in the near future and rather provides the potential to continue future, transformational processes since the required logistics network do not exist yet and current systems thinking limits the sharing of existing logistics infrastructure.

Looking closer at sustainable business models for LSPs itself, the 1PL to 6PL classification scheme does not fit the existing business model ontologies and archetypes. While authors have started to consolidate the literature on sustainable business models by introducing sustainable business model ontologies and archetypes in recent years [15], they neglected the nature of LSPs as service provider for sustainable niche players and globally acting companies alike. 
For instance, Bocken et al. [18] distinguish between eight different sustainable business model archetypes: (1) promoting maximization of material and energy efficiency; (2) creation of value from waste; (3) substitution with renewable and natural processes; (4) delivery of functionality rather than ownership; (5) adoption of a stewardship role; (6) encouraging sufficiency; (7) repurposing products and services for society and environment; and (8) the development of scale-up solutions. In this line, the 6PL business model can adopt all of these business model archetypes. Accordingly, future research should foster transformative business model innovation approaches for certain business model (arche-)types in other industries [51].

\section{Conclusions and Outlook}

Purpose of this explorative study was to provide a structured analysis of sustainability pathways for logistics business transformation. In this line, the authors conducted a two-stage approach by (a) knowledge production with expert interviews and (b) systematically evaluating the results with the help of quantitative approaches. By doing so, the present study defines LSP's retention strategies to meet future societal and environmental requirements. In addition, the study contributes to theory by constructing the Lead Sustainability Service Provider (6PL) business model (arche)type and its role in societal transitions.

However, applying qualitative and quantitative research methods is not free of limitations that can be addressed in future research activities. Therefore, future work can further address the people dimension in logistics and supply chain management, for instance by testing the empirical results with a survey. Moreover, the logistics industry comprises the primary focus of this study. Hence, the findings are not generalizable for other industry contexts and, accordingly, provide opportunities for future research.

Author Contributions: The authors designed the study jointly. T.G. conducted the data collection of the interviews P1-P6 and S1-S6 and the analysis of the interviews. T.G. contributed mainly to theory building as well as to the writing of all sections of the article. A.M. also contributed to the writing of this article. K.K. developed the initial underlying research design for the 6PL concept and contributed to the revision of the article.

Funding: We gratefully acknowledge the financial support from the German Federal Ministry of Education and Research (FKZ 01UT1406B).

Acknowledgments: The research activities of this study are connected to the research project "ILoNa" (Innovative Logistik für nachhaltige Lebensstile) (2015-2018). We would like to thank Imke Schmidt, who jointly conducted the data collection of the interviews P1-P6 and S1-S6 and the analysis of the interviews. Moreover, we would like to thank Rosa Strube and Thomas Wagner from the Collaborating Centre on Sustainable Consumption and Production (CSCP) in Wuppertal, who conducted expert interviews S7-S12 and the analysis of these interviews. We would also like to thank Alireza Sohofi and Jan Eiten from the Centre for Logistics and Traffic at the University of Duisburg-Essen for supporting the research activities of this study.

Conflicts of Interest: The authors declare no conflict of interest.

\section{Appendix}

1. Introduction
a. Introduction to the study, its aims and the researcher
b. Assurance of confidentiality and anonymity

2. Logistics and sustainability

a. What are the most important sustainability hot spots related to logistics services (incl. the LM) from a social, ecological and economical perspective?

b. What are the main drivers for sustainable logistics services? Which trends support sustainable logistics services?

c. What are the main barriers to sustainable logistics services? Which trends constrain sustainable logistics services? 
3. Designing more sustainable SCs

a. What role do logistics service providers play in designing a more sustainable SC?

b. What role do other actors in the SC play?

c. How can Sharing and Circular Economy solutions contribute in designing a more sustainable SC?

4. Sustainable logistics and sustainable consumption

a. Where/when do logistics service providers interact directly/indirectly with consumers?

b. How important are information technologies to bring logistics service providers and consumers together?

c. Are there any initiatives to inform consumers about sustainable logistics services?

\section{References}

1. Tozanli, O.; Duman, G.M.; Kongar, E.; Gupta, S.M. Environmentally Concerned Logistics Operations in Fuzzy Environment: A Literature Survey. Logistics 2017, 1, 4. [CrossRef]

2. Schaltegger, S.; Hansen, E.G.; Lüdeke-Freund, F. Business models for sustainability: Origins, present research, and future avenues. Organ. Environ. 2016, 29, 3-10. [CrossRef]

3. Schaltegger, S.; Lüdeke-Freund, F.; Hansen, E.G. Business models for sustainability: A co-evolutionary analysis of sustainable entrepreneurship, innovation, and transformation. Organ. Environ. 2016, 29, 264-289. [CrossRef]

4. Brandenburg, M.; Rebs, T. Sustainable supply chain management: A modeling perspective. Ann. Oper. Res. 2015, 229, 213-252. [CrossRef]

5. Judge, W.Q.; Douglas, T.J. Performance implications of incorporating natural environmental issues into the strategic planning process: An empirical assessment. J. Manag. Stud. 1998, 35, 241-262. [CrossRef]

6. Peattie, K. Environmental Marketing Management: Meeting the Green Challenge; Pitman: London, UK, 1995.

7. Sarkis, J. A strategic decision framework for green supply chain management. J. Clean. Prod. 2003, 11, 397-409. [CrossRef]

8. Seuring, S.; Müller, M. From a literature review to a conceptual framework for sustainable supply chain management. J. Clean. Prod. 2008, 16, 1699-1710. [CrossRef]

9. Carter, C.R.; Jennings, M.M. The role of purchasing in corporate social responsibility: A structural equation analysis. J. Bus. Logist. 2004, 25, 145-186. [CrossRef]

10. Nikolaou, I.E.; Evangelinos, K.I.; Allan, S. A reverse logistics social responsibility evaluation framework based on the triple bottom line approach. J. Clean. Prod. 2013, 56, 173-184. [CrossRef]

11. Tan, R.B.H.; Khoo, H.H. An LCA study of a primary aluminum supply chain. J. Clean. Prod. 2005, 13, 607-618. [CrossRef]

12. Carter, C.R.; Jennings, M.M. Logistics social responsibility: An integrative framework. J. Bus. Logist. 2002, 23, 145-180. [CrossRef]

13. Gruchmann, T. Advanced Green Logistics Strategies and Technologies. In Operations, Logistics and Supply Chain Management; Zijm, H., Klumpp, M., Regattieri, A., Heragu, S., Eds.; Springer: Cham, Switzerland, 2019; pp. 663-686.

14. Boons, F.; Lüdeke-Freund, F. Business models for sustainable innovation: State-of-the-art and steps towards a research agenda. J. Clean. Prod. 2013, 45, 9-19. [CrossRef]

15. Neumeyer, X.; Santos, S.C. Sustainable business models, venture typologies, and entrepreneurial ecosystems: A social network perspective. J. Clean. Prod. 2018, 172, 4565-4579. [CrossRef]

16. Lüdeke-Freund, F.; Gold, S.; Bocken, N. Sustainable business model and supply chain conceptions-Towards an integrated perspective. In Implementing Triple Bottom Line Sustainability into Global Supply Chains; Greenleaf Publishing: Sheffield, UK, 2016; pp. 345-375.

17. Boschian, A.; Paganelli, P. Business models for advanced ICT in logistics. In Sustainable Logistics and Supply Chains; Lu, M., De Bock, J., Eds.; Springer: Cham, Switzerland, 2016; pp. 15-51.

18. Bocken, N.M.; Short, S.W.; Rana, P.; Evans, S. A literature and practice review to develop sustainable business model archetypes. J. Clean. Prod. 2014, 65, 42-56. [CrossRef] 
19. Köylüoglu, G.; Krumme, K. Kriterienfindung für nachhaltige Geschäftsprozesse in der Logistik-Eine Aufarbeitung bestehender Probleme und möglicher Chancen. In Corporate Social Responsibility in der Logistikbranche: Anforderungen an Eine Nachhaltige Unternehmensführung; Erich Schmidt Verlag: Berlin, Germany, 2014.

20. Wolf, C.; Seuring, S. Environmental impacts as buying criteria for third party logistical services. Int. J. Phys. Distrib. Logist. Manag. 2010, 40, 84-102. [CrossRef]

21. Schaltegger, S.; Wagner, M. Sustainable entrepreneurship and sustainability innovation: Categories and interactions. Bus. Strategy Environ. 2011, 20, 222-237. [CrossRef]

22. Hockerts, K.; Wüstenhagen, R. Greening Goliaths versus emerging Davids-Theorizing about the role of incumbents and new entrants in sustainable entrepreneurship. J. Bus. Ventur. 2010, 25, 481-492. [CrossRef]

23. Nelson, R.R.; Winter, S.G. Evolutionary theorizing in economics. J. Econ. Perspect. 2002, 16, 23-46. [CrossRef]

24. Agrawal, S.; Singh, R.K.; Murtaza, Q. Triple bottom line performance evaluation of reverse logistics. Compet. Rev. 2016, 26, 289-310. [CrossRef]

25. Frehe, V.; Mehmann, J.; Teuteberg, F. Understanding and assessing crowd logistics business models-using everyday people for last mile delivery. J. Bus. Ind. Mark. 2017, 32, 75-97. [CrossRef]

26. Botsman, R.; Rogers, R. What's Mine Is Yours-How Collaborative Consumption Is Changing the Way We Live; Harper Collins Publisher: London, UK, 2011.

27. Batista, L.; Bourlakis, M.; Smart, P.; Maull, R. Business Models in the Circular Economy and the Enabling Role of Circular Supply Chains. In Operations Management and Sustainability; Palgrave Macmillan: Cham, Switzerland, 2019; pp. 105-134.

28. Vachon, S.; Klassen, R.D. Extending green practices across the supply chain: The impact of upstream and downstream integration. Int. J. Oper. Prod. Manag. 2006, 26, 795-821. [CrossRef]

29. Bankes, S. Exploratory modeling for policy analysis. Oper. Res. 1993, 41, 435-449. [CrossRef]

30. Kwakkel, J.H.; Pruyt, E. Exploratory Modeling and Analysis, an approach for model-based foresight under deep uncertainty. Technol. Forecast. Soc. Chang. 2013, 80, 419-431.

31. Walker, W.E.; Haasnoot, M.; Kwakkel, J.H. Adapt or perish: A review of planning approaches for adaptation under deep uncertainty. Sustainability 2013, 5, 955-979. [CrossRef]

32. Lempert, R.J.; Popper, S.W.; Bankes, S.C. Shaping the Next One Hundred Years: New Methods for Quantitative, Long-Term Policy Analysis; Rand: Santa Monica, CA, USA, 2003.

33. Kwakkel, J.H.; Walker, W.E.; Marchau, V.A.W.J. Assessing the efficacy of adaptive airport strategic planning: Results from computational experiments. Environ. Plan. B Plan. Des. 2012, 39, 533-550. [CrossRef]

34. Halim, R.A.; Kwakkel, J.H.; Tavasszy, L.A. A scenario discovery study of the impact of uncertainties in the global container transport system on European ports. Futures 2016, 81, 148-160. [CrossRef]

35. Corvers, R. Scenario Discovery in Supply Chain Risk Management; Delft University of Technology: Delft, The Netherlands, 2016.

36. Moallemi, E.A.; Elsawah, S.; Ryan, M.J. Model-based multi-objective decision making under deep uncertainty from a multi-method design lens. Simul. Model. Pract. Theory 2018, 84, 232-250.

37. Mayring, P.; Fenzl, T. Qualitative Inhaltsanalyse. In Handbuch Methoden der Empirischen Sozialforschung; Baur, N., Blasius, J., Eds.; Springer: Wiesbaden, Germany, 2014; pp. 543-556.

38. Alvesson, M. Beyond neopositivists, romantics, and localists: A reflexive approach to interviews in organizational research. Acad. Manag. Rev. 2003, 28, 13-33. [CrossRef]

39. Yin, R.K. Case study research: Design and methods. In Applied Social Research Methods Series; Sage: Thousand Oaks, CA, USA, 2003.

40. Riege, A.M. Validity and reliability tests in case study research: A literature review with "hands-on" applications for each research phase. Qual. Mark. Res. Int. J. 2003, 6, 75-86. [CrossRef]

41. Bradfield, R.; Wright, G.; Burt, G.; Cairns, G.; Van Der Heijden, K. The origins and evolution of scenario techniques in long range business planning. Futures 2005, 37, 795-812. [CrossRef]

42. Jayaraman, V. Transportation, facility location and inventory issues in distribution network design. Int. J. Oper. Prod. Manag. 1998, 18, 471-494. [CrossRef]

43. Jain, A.K. Data clustering: 50 years beyond K-means. Pattern Recognit. Lett. 2010, 31, 651-666. [CrossRef]

44. Laporte, G. The traveling salesman problem: An overview of exact and approximate algorithms. Eur. J. Oper. Res. 1992, 59, 231-247. [CrossRef] 
45. Hübner, A.H.; Kuhn, H.; Sternbeck, M.G. Demand and supply chain planning in grocery retail: An operations planning framework. Int. J. Retail. Distrib. Manag. 2013, 41, 512-530. [CrossRef]

46. Spence, L.; Bourlakis, M. The evolution from corporate social responsibility to supply chain responsibility: The case of Waitrose. Supply Chain Manag. Int. J. 2009, 14, 291-302. [CrossRef]

47. Wollenburg, J.; Hübner, A.; Kuhn, H.; Trautrims, A. From bricks-and-mortar to bricks-and-clicks: Logistics networks in omni-channel grocery retailing. Int. J. Phys. Distrib. Logist. Manag. 2018, 48, 415-438. [CrossRef]

48. Schmidt, I. Consumer Social Responsibility: Gemeinsame Verantwortung für Nachhaltiges Konsumieren und Produzieren; Springer: Berlin, Germany, 2016.

49. Bidmon, C.M.; Knab, S.F. The three roles of business models in societal transitions: New linkages between business model and transition research. J. Clean. Prod. 2018, 178, 903-916. [CrossRef]

50. Gruchmann, T.; Seuring, S. Explaining logistics social responsibility from a dynamic capabilities perspective. Int. J. Logist. Manag. 2018. [CrossRef]

51. Gorissen, L.; Vrancken, K.; Manshoven, S. Transition thinking and business model innovation-Towards a transformative business model and new role for the reuse centers of Limburg, Belgium. Sustainability 2016, 8, 112. [CrossRef]

(C) 2018 by the authors. Licensee MDPI, Basel, Switzerland. This article is an open access article distributed under the terms and conditions of the Creative Commons Attribution (CC BY) license (http://creativecommons.org/licenses/by/4.0/). 